\title{
El nuevo rumbo de la vigésima segunda edición (2001) del Diccionario de la lengua española de la Real Academia
}

Juan Gutiérrez Cuadrado

Universidad de Barcelona

\section{MODUS INTERPRETANDI}

Los rumores sobre las novedades que encerraba el Diccionario Académico del 2001 habían disparado, antes de que saliera a la luz, la curiosidad de muchos lexicógrafos y de otros profesionales como editores, traductores, periodistas, etc. Tras su aparición, dejando de lado la comprensible campaña comercial alabanciosa, diversos comentarios aparecidos en diferentes diarios y revistas han puesto de relieve virtudes y defectos del Diccionario, pero, sobre todo, como resultado tangencial no previsto, la necesidad de juzgar el Diccionario Académico con un patrón adecuado. En efecto, no parece que actualmente pueda usarse la misma vara de medir que usaba Antonio de Valbuena, divertida algunas veces, pero desacertada en muchísimas ocasiones ${ }^{1}$. Por eso, antes de fijarme en el Diccionario, no juzgo inoportuno exponer algunas reflexiones previas.

Situémonos en el constructivismo de la filosofía práctica. En un momento dado de su respuesta a los críticos, un autor como Schwemmer expone que, antes de entrar en una discusión sistemática, hay necesidad

1 Recordaré solo un libro de los que dedicó el autor a la Academia: Antonio de Valbuena 1896. Valbuena descubre "disparates", "errores", "majaderías", etc. en el Diccionario Académico con suma facilidad; sin embargo, su incomprensión de lo que es un diccionario y su desenfado metodológico convierten su texto en un pasatiempo sin interés especial, aunque algunas observaciones sean correctas. 
de aclarar "qué haya de entenderse por 'interpretación' y especialmente por 'interpretación correcta (o 'adecuada')' si antes no se da respuesta a las cuestiones acerca de con qué intención leemos los textos $\mathrm{y}$, por consiguiente, qué es lo que debemos exigir como resultado de una lectura llevada a cabo con una determinada intención" (1978: 161-162). Para esbozar una estrategia de la discusión considera importante distinguir entre la demostración del error, las diferencias de opinión y los malentendidos. Me parece necesario partir de estos supuestos para criticar el Diccionario de la Real Academia. Si no se manifiesta previamente qué intención ha guiado al crítico en la lectura del texto y, una vez leído, no se es consciente de la necesidad de demostrar los errores, proclamar las diferencias de opinión y señalar los posibles malentendidos, la crítica no contribuirá a la comprensión ni a la mejora de la obra o del texto criticado. Se comprobará enseguida que estoy interesado en exponer algunas diferencias de opinión, no tanto con la realización del Diccionario sino con su concepción.

Si se quiere enjuiciar el Diccionario Académico es necesario no perder de vista sus fundamentos textuales: a) es un texto corporativo; $b$ ) avalado por una institución oficial, tradicional y con vocación hispánica; c) elaborado, al menos formalmente, respetando las reglas corporativas (es decir, resulta ocioso apuntar que el académico X es el responsable de la decisión Y). El Diccionario refleja, por consiguiente, el pensamiento corporativo de la Academia y no equivale exactamente al conjunto de reflexiones de todos los académicos ni representa, tampoco, la opinión de algunos miembros determinados. La Academia se manifiesta corporativamente en las obras que firma con su nombre o en los escritos y comunicados que publica como corporación. Y como otras instituciones parecidas tienen sus propios procedimientos para decidir sus opiniones institucionales, así la Academia tiene sus propias maneras de trabajar y de tomar decisiones. La obligación de los críticos es juzgar el resultado de los trabajos académicos. Decidir los procedimientos para trabajar de una u otra manera es responsabilidad de la propia Academia.

Los fundamentos del Diccionario por sí mismos no son beneficiosos ni perjudiciales, pero están presentes en cualquier página y han conformado algunas características notables que no pueden pasarse por alto: 
a) Aunque todo diccionario difunda una norma por el mero hecho de haber salido a la luz, el Diccionario de la Academia es un texto normativo por antonomasia. La prueba de que funciona como norma social es que sirve de referencia en algunos concursos de radio o televisión, en los tribunales de justicia o en el Congreso de los Diputados, y que otros varios diccionarios marcan los lemas o las acepciones que no figuran en el Diccionario de la Real Academia. Por ello ningún otro diccionario español tiene que soportar la presión de las discusiones sobre la norma a la vez que la exigencia social de que recomiende con lucidez una norma clara.

b) El Diccionario académico es un texto que nace sin afán de lucro. La Academia es una institución oficial y, a pesar de algunas opiniones muy difundidas, la virtud de los trabajos académicos no se mide por las listas de ventas. Por ejemplo, no conozco a ningún filólogo que haya censurado el ranking de ventas del Diccionario de Autoridades o que haya alabado el último Diccionario Escolar de la Academia, por más ingresos que haya proporcionado.

c) El Diccionario académico es un texto tradicional. En el prólogo se advierte: "Por otro lado, se ha puesto en práctica la idea tradicional de 'verter el vino viejo en odres nuevos', acomodando en lo posible todo ese contenido a la estructura fijada por la Nueva Planta" (p. XXVII). ¿Hubiera sido útil consultar a un enólogo de alguna bodega de reconocido prestigio para aprovechar su experiencia en el trasvase de caldos?

d) El Diccionario académico tiene vocación panhispánica (p. X). Como es sabido, tras la independencia de los antiguos virreinatos americanos, algunos académicos de la metrópoli siguieron manteniendo buenas relaciones con ciertos autores de las jóvenes Repúblicas Americanas y a finales del siglo XIX apoyaron la creación de Academias correspondientes. Las relaciones difíciles y escasas del siglo XIX han desembocado tras un largo recorrido en la Asociación de Academias, que dispone de una Comisión Permanente. Es comprensible, por ello, que en el Diccionario se documenten muchos americanismos.

e) El Diccionario académico es una obra corporativa. Sin embargo, la vigésima segunda edición del 2001 marca un nuevo rumbo muy es- 
peranzador en la presentación del trabajo corporativo, pero que me parece, se le ha prestado poca atención al hecho. Fijémonos en lo que los franceses llaman peritexto ${ }^{2}$ : la edición del Diccionario Académico del 2001 no puede medirse con el mismo patrón de las anteriores. La Academia ha ido modificando en sus diversas ediciones pequeños detalles de la organización general del Diccionario y, a veces, ha cambiado, también, sus criterios lexicográficos. Merece la pena recordar la edición de $1780^{3}$, en la que tuvo lugar el cambio esencial de la historia académica, la supresión de los ejemplos, auténtica catástrofe para la lexicografía española. Otros cambios dignos de mención pueden observarse en la edición de 1869, en la que se suprimen las correspondencias latinas, y, sobre todo, en la de 1884, donde se indicaron las etimologías por primera vez y se abrieron las puertas a un raudal de voces técnicas $\mathrm{y}$ a un grupo numeroso de americanismos ${ }^{4}$. Pues bien, la edición del 2001 presenta una manera de trabajar absolutamente nueva en la ya larga vida de la Academia: por primera vez en el peritexto autorial se cita "la colaboración inestimable del Instituto de Lexicografía", se nombra a sus miembros y se agrupan alfabéticamente los colaboradores externos que "han prestado su ayuda en distintas tareas". Con esta decisión la Academia ha repartido públicamente la responsabilidad y, a la vez, el mérito entre todos los colaboradores, pero también distribuye las críticas negativas que lleguen, si llegan, entre todos ellos. Por eso la novedad estratégica más importante de esta edición es el peritexto. Aquí están condensados el manifiesto de una nueva manera de trabajar y la promesa de frutos más sazonados. La propia Academia (p. XXXI) enumera las tareas pendientes $\mathrm{y}$, como en algunas ediciones anteriores, pi-

2 'Nous l'avons vu (tableau, p. 18), le paratexte de l'auteur se compose de deux ensembles de productions : le péritexte auctorial (nom d'auteur, titres et intertritres, préfaces et avertissements, épigraphes, notes) et l'épitexte auctorial (épitexte privé regroupant correspondance, confidences...)" (Lane 1992 : 41).

3 En el prólogo de esta edición se advertía que el Diccionario se había reducido de seis tomos a uno solo, "sin quitar ninguna voz ni alterar la obra en cosa substancial". Los ejemplos, por consiguiente, no se consideraban algo sustancial.

4 Prólogo del Diccionario de 1884; Cecilio Garriga (2001) ha comprobado el notable aumento de tecnicismos. 
de la benevolencia del lector ("comprensión, paciencia y apoyo"). Al estar convencido también de que "la calidad del empeño común lo merece sobradamente", centraré mi crítica, sobre todo, en la concepción del Diccionario académico, porque me parece poco pertinente elaborar un listado de las equivocaciones (que no escasean, como en cualquier obra de este tipo). Sin embargo, será obligado comentar algunos errores al tratar ciertas cuestiones para que el discurso conserve su coherencia. Pero lo que tiene interés, me parece, es que se discutan abiertamente las ideas esenciales que marcan la orientación del Diccionario. Si esta crítica ayuda a mejorarle alguna línea me daré por satisfecho, pues así devolveré a la Docta Corporación parte de su contribución a esta reseña: me hubiera sido mucho más difícil escribirla si no se hubieran colgado en Internet los materiales del CREA y del CORDE, y las distintas ediciones de su Diccionario.

\section{EL DICCIONARIO GENERAL DE USO}

Todo diccionario ofrece una información limitada en un espacio físico limitado. Los responsable académicos del Diccionario, como cualquier otro lexicógrafo, deben elegir qué información verterán en el volumen del Diccionario. Por tanto, como el espacio disponible no es ilimitado, la inclusión de una información supone la exclusión de otra. Por otro lado, parece también evidente que cualquier diccionario compone una imagen del léxico de una lengua:

...le diccionnaire dit "de langue", et avec lui le dictionnaire hybride (encyclopédie), ne décrit nullement le système abstrait, il en exemplifie des actualisations, ce qui est bien différent. Non plus, il ne décrit "le" discours, tâche inachevable, mais utilise une sélection de discours à ses fins propres, qui sont-enfin-de décrire des usages, avec leurs dimensions sémantiques, pragmatiques, et culturelles. Cette description intensément sélective d'usages construit une "image" (et non pas un modèle scientifique, et non pas une photo fidèle) d'où peut, à travers les conflits des normes évaluatives, se dégager ou non la figure d'une norme unique (A. Rey 1983 : 543).

En este aspecto tampoco es diferente el Diccionario académico de los otros. Por ello, lo primero que conviene preguntarse es qué imagen 
léxica del español quiere ofrecer el Diccionario académico. Creo que la Academia es muy consciente de su historia y conoce perfectamente los cimientos de su Diccionario. Precisamente por ello, el plan de la última edición es excesivamente ambicioso y, casi con seguridad, inalcanzable, tal como han evolucionado las sociedades y la lexicografía de nuestro tiempo, y tal como se presentan actualmente las relaciones entre las distintas comunidades y los países que hablan español. En efecto, en la presente edición del Diccionario todavía se nos promete varios diccionarios en uno: histórico, general usual, dialectal, hispanoamericano y normativo. No es fácil conseguir que tantos instrumentos juntos funcionen. Los aficionados al bricolaje saben de sobra que algunos juegos de herramientas multiuso son poco útiles a la hora de la verdad. Por eso prefieren disponer de herramientas específicas de toda confianza, que los sacarán de apuros cuando lo necesiten, y completar, poco a poco, la colección infinita de chismes que ofrecen las ferreterías especializadas, para arreglar cualquier avería casera. Por ello, ahora que la Academia nos ha sorprendido con un preámbulo y unas advertencias tan diferentes a las de las ediciones anteriores (desde Autoridades ningún prólogo encierra tanta importancia), bueno sería que la Academia empezara a planear seriamente el tipo de diccionario que quiere elaborar. Ya ha editado un Diccionario Escolar y está elaborando un diccionario de dudas. Como han hecho muchas editoriales en todo el mundo, nada impide que la Academia cambie el Diccionario por los Diccionarios. Solo pensando en una serie podrá elaborar el Diccionario normativo y de uso que necesita la lengua española. Me parece que ya ha pasado el tiempo de elaborar un solo diccionario, resumen y reunión de los que se necesitan.

Parece natural que el primer diccionario que elabore la Academia sea un Diccionario general de uso, que sirva de referencia normativa morfológica y ortográfica a toda la comunidad hispana y de norma léxica culta del habla urbana. No me parece difícil ponerse de acuerdo en las variedades morfológicas del español que deben figurar en el diccionario, como no ha sido imposible ponerse de acuerdo en los aspectos ortográficos. Si acaso, debe contarse con las críticas que ha despertado la Ortografía. Los comentarios de Moreno de Alba, por ejemplo, que 
echa de menos una norma clara y sistemática me parecen ejemplares. En el caso de la morfología, la norma -o las normas- podrían ser varias, pero precisas.

Otro problema diferente es la norma culta léxica. Debería ser urbana, desde luego. No por desprecio al campo sino porque la sociedad actual es urbana, las novedades son urbanas e, incluso, las novedades que aparezcan en el campo serán modalidades relacionadas con el mundo industrial y urbano (nuevos tipos de alimentos para el ganado, nuevos tipos de semillas, nuevos tipos de máquinas, cercas, riego y construcciones...). Aún más, ciertas ideologías relacionadas con la agricultura ecológica y la defensa de la naturaleza nacen en la geografía urbana y no rural. El campo tradicional ha quedado en los atlas lingüísticos, en las monografías dialectales y en las bibliotecas. Por ello es tan importante en España e Hispanoamérica la recogida de materiales en el campo para la antropología, la sociología y la dialectología, pero no para el Diccionario. Por ello pueden resultar engañosos el ruralismo o pintoresquismo que aparece en ciertos documentales o crónicas de viajes de Hispanoamérica. Porque en Hispanoamérica las diferencias entre campo y ciudad son, sin duda, importantísimas, pero la sociedad urbana marca los modos de vivir, aunque lo haga con menos recursos y con más dificultades que en la Península. Por ello, la dialectología actual más viva no es la del campo sino, como sucede en España, la de las ciudades. Ahora bien, dicho esto, no es tan fácil elegir la nomenclatura de esta norma urbana. Si se trata de una norma urbana peninsular, no percibo dificultades irresolubles. Si se quiere contar también con las diferentes normas urbanas hispanoamericanas las dificultades me parecen más que considerables. Es una cuestión que tiene que decidir la Asociación de Academias, aunque no sobraría que consultara también la opinión de algunos grupos de filólogos y lexicógrafos que trabajan fuera de la Academia en diferentes puntos del mundo hispánico. Si se piensa en las voces y acepciones que deberían figurar en un Diccionario hispánico habría que pensar, por lo menos, en: a) las voces y acepciones cultas interhispánicas (que diría Raúl Ávila); b) el léxico culto urbano peninsular; c) las voces y acepciones cultas urbanas hispanoamericanas; d) las voces tradicionales literarias vivas en la mayor parte 
del dominio hispanoamericano o peninsular, tengan los significados que tengan. El problema, sin embargo, sobrepasa con mucho la selección de la nomenclatura, como mostraré más adelante, y no me parece que pueda solucionarse por este camino. Debe comprenderse que no basta solamente con buena voluntad sino que exigirá un trabajo estratégico continuado e inteligente. Y, se decida lo que se decida, habría que empezar ya a sistematizar los neologismos científicos en el mundo hispánico, como don Rafael Lapesa proponía repetidamente. La conclusión provisional, de todas maneras, es bien sencilla: si un diccionario de uso peninsular, con carácter normativo cerrado en algunas o en muchas cuestiones, no es muy complicado actualmente de elaborar, un diccionario hispánico es, de momento, un objetivo inalcanzable. Por ello no es extraño que la Academia incluya tantos hispanoamericanismos en la presente edición.

\section{DICCIONARIO DE HISPANOAMERICANISMOS}

Si se comparan las acepciones del léxico peninsular y las hispanoamericanas, las diferencias son notables. Fijémonos, por ejemplo, en el lema chapola; podemos leer "f. Col. mariposa (\|insecto)". Fijémonos en el lema equivalente en un diccionario bilingüe de bolsillo alemán (Langenscheidt, 1927): "falter m. Lepidóptero, mariposa f.". La entrada equivalente en el Collins Pocket, 1982: "butterfly n. mariposa". Si se olvida que he suprimido la pronunciación figurada en estos dos últimos casos, puede afirmarse sin grave error que las tres entradas se parecen mucho entre sí. El diccionario alemán y el de la Academia comparten, además, dejando de lado la representación gráfica, la relación de mariposa o con insecto o con lepidóptero. Examinemos el lema mariposa del Diccionario académico:

De Mari, apóc. de María, y posa, 2. ${ }^{a}$ pers. sing. del imper. de posar.

1. f. Insecto lepidóptero.

2. Pájaro común en la isla de Cuba.... [...].

6. Taurom. Suerte de correr las reses abanicando con el capote a la espalda y dando el diestro la cara al toro.

$[\ldots]$ 
12. m. coloq. Hombre afeminado u homosexual.

$\| \sim$ de la muerte. $f$. La que tiene sobre el dorso del tórax unas manchas que forman un dibujo parecido a una calavera. $\| \sim$ de la seda. $f$. Aquella cuya oruga produce la seda que se utiliza en la industria más comúnmente, y en general todas las que tienen orugas productoras de seda. $\square$ V. corbata de ...

Lo primero que cualquier lector español podría preguntarse es: ¿Cómo se llaman en Colombia las corbatas de mariposa? ¿Hay chapolas de la muerte y chapolas de la seda en Colombia? ¿Puede emplearse chapola en el mismo sentido que la acepción 12 de mariposa en la Península? Si el lector no se hace normalmente estas preguntas es por una sencilla razón: usa los lemas hispanoamericanos como si estuvieran en un diccionario bilingüe (muy elemental, por cierto). En efecto, un lector español que encuentre el enunciado colombiano "las alas de la chapola" consultará el Diccionario de la Academia y podrá decodificar "las alas de la mariposa"; pero si el mismo lector lee el enunciado "el transplante de la chapola" en un texto de caficultura, el Diccionario académico no le sirve de ayuda. Y si, además, encuentra una página del periódico que le anuncia "chapola informativa", puede sentir cierta extrañeza. En realidad no está bien caracterizar estos lemas como propios de un diccionario bilingüe, pues pertenecerían con más propiedad a un diccionario contrastivo asimétrico. Por eso, si recorremos el camino en dirección contraria podemos suponer (solo una suposición) que un lector colombiano no ignora el significado de "las alas de la mariposa" (pues mariposa no está marcado como Esp.). Ahora bien, esta suposición general negativa, lo no marcado como Esp. no resulta desconocido a los hispanoamericanos, resulta poco didáctica: ¿Conocen los colombianos las diferentes acepciones peninsulares de mariposa?

A pesar de todo, no cabe duda que los hispanoamericanismos que incluye la presente edición del Diccionario han sido actualizados y que están mejor atribuidos a las respectivas zonas geográficas que en otras ediciones anteriores. Aportan una información útil, pero insuficiente. En efecto, faltan: a) voces y acepciones muy frecuentes en los diversos países; b) ejemplos; c) referencias internas; d) un buen sistema de marcado; e) la visión estereotípica de la realidad hispanoamericana... 
Es evidente que faltan voces comunes y esto no necesita especial demostración. Me fijo en algunos ejemplos: En La Prensa (El Diario de los Nicaragüenses) del 24 de enero del 2002 se lee el título de un artículo "Ni pepena ni repela". Repela no figura en el Diccionario de la Academia, a pesar de que incluye voces y acepciones de Nicaragua. Se incluye, en cambio, pepena:

Pepena f. Am. Cen. y Méx. Acción y efecto de pepenar. \| 2. Nic.

Resto de carne que se adhiere a las ollas al freír la corteza del cerdo.

Bajo pepenar se documenta: "(del nahua pepena, escoger, recoger) tr. Am. Cen. y Méx. Recoger del suelo, rebuscar. $\|$ 2. Nic. suspender a un alumno. || 3. prnl. coloq. El Salv. matar (|| 2. quitar la vida). || 4. Méx. y Nic. robar (\| hurtar de cualquier modo). Además en el Diccionario figura pepenador, ra "m. y f. Méx. persona que pepena". (¿Persona que recoge del suelo y rebusca, persona que roba, o persona que roba o recoge?).

El problema que nos plantea el periódico de Nicaragua es algo difícil de solucionar con el Diccionario académico. La información que incluye el Diccionario es cierta, pero parcial. Por eso algunos lectores, una vez más, pueden confundirse. En efecto, pepena en el texto nicaragüense se relaciona con la acepción primera de pepenar y equivale a 'recolecta de granos [de café] maduros caídos' según la glosa que puede leerse en el propio texto; repela equivale a 'el último corte' para preparar la planta.

Por otro lado, pepena, pepenar y pepeneros, tal como se definen para México, no dejan de resultar ambiguos. El pepenero es el que está rebuscando en el tiradero (vertedero) y selecciona diferentes materiales para clasificarlos y venderlos. En la ciudad de México hay conocidas organizaciones de pepeneros. Pero esta es otra cuestión: no solo se necesita una buena selección de lemas, una correcta ejemplificación, un buen conjunto de marcas (no me referiré a ellas aquí), y una información adecuada. Además es necesario en la definición contar con los estereotipos de la sociedad que maneja la lengua. La definición de basurero me resulta suficiente para hacerme una idea de los basureros españoles. Yo sé, además, que de vez en cuando hay huelgas de recogida de 
basuras que hacen, curiosamente, no los basureros sino los empleados de las empresas que tienen las contratas municipales de basuras o, quizá, los empleados encargados de la recogida de basuras. En España había basureros cuando éramos niños. Ahora nos recogen las basuras, gracias a Dios, empleados de empresas de basuras o de los servicios municipales de limpieza. Y en España estos trabajadores no tienen nada que ver con la nueva y creciente actividad que desde hace unos años hasta ahora ejercen en las grandes ciudades españolas las personas que rebuscan comida en los contenedores de los supermercados. Basta con leer algunos lemas relacionados con la cultura o con la historia en el Diccionario del español de México dirigido por Luis Fernando Lara para comprender que es imposible la tarea de injertar un diccionario de hispanoamericanismos en el Diccionario académico. El pepenero se llama en la capital de Managua churequero (de La Chureca, el topónimo del vertedero). Y en Colombia los pepeneros, con una organización ejemplar en el mundo, se agrupan en la Asociación Nacional de Recicladores (no documentada en el Diccionario de la Academia), voz que, por supuesto, no puede definir a "la persona que recicla" (aunque se refiera a personas que, efectivamente, trabajan reciclando la basura).

Para olvidarnos de los que sobreviven removiendo los vertederos recordemos que no todas las ciudades disponen de servicio de limpieza municipal. San Salvador, al menos, dispone de un servicio de Aseo Municipal. Y este ejemplo nos recuerda otra cuestión lexicográfica: que las palabras se enganchan en el discurso como las cerezas. Por eso no importa solo elegir un lema sino, además, las lexías, colocaciones, etc. de las que forma parte. No sé si en Nicaragua el adj. cultural equivale al mismo adjetivo peninsular. Lo que sí es cierto es que en España ningún campesino hablará de las labores culturales de la viña, a diferencia de lo que puede escribirse en Nicaragua del café: "labores culturales (chapoda o limpieza, fertilización, fumigación)". Los ejemplos podrían acumularse sin especial esfuerzo y sin necesidad de consultar la colección de diccionarios contrastivos que han elaborando los Profesores Haensch y Werner. Para ello basta con disfrutar leyendo en Internet la información de Hispanoamérica.

Otra cuestión que plantean los hispanoamericanismos es el de la 
ejemplificación. En efecto, la última edición del Diccionario académico ha incrementado los ejemplos, aunque la Academia se inclina más a mezquina que a liberal en este punto. En las pp. 1384-1385 (linfáticolira), elegidas al azar, se leen ejemplos en dos acepciones del lema liquidar. En estas dos páginas aparecen varios americanismos (linternear, linyera, lipidia, lipidiar, lipón, lipudo, liquidambo, liquilique). Ningún lema ni acepción hispanoamericanos incluye ejemplos. ¿Por qué no se ha aprovechado la profunda revisión que se anuncia en el preámbulo para ejemplificar los hispanoamericanismos? Pero ni siquiera deberíamos conformarnos con la definición y los ejemplos. Lipidia tiene dos acepciones. La primera parece no contable ("miseria extrema") y se supone que el plural tendrá, si se usa, valor enfático. Pero la segunda acepción "discusión insistente y fastidiosa" es contable. Debe suponer, por ello, el lector del Diccionario que encontrarse con lipidias será normal en este segundo caso. ¿Está el lector equivocado? El Diccionario no disipa la duda.

A pesar de todo, salta a la vista que la Academia en esta edición del Diccionario ha cuidado mucho más que antes la distribución geográfica de las voces y acepciones americanas, ha podado muchos términos y acepciones desusados y ha incluido otros nuevos (por ejemplo, pepene$r o$ ). Como ya he comentado, esta información es útil. En realidad, cualquier información del diccionario que no provoque confusión en el lector y sea acertada no debe ser censurada, pero, quizá, puede ser mejorada. Si el número de americanismos y la información ligada a ellos crece en el Diccionario académico, crecerá su utilidad, pero, al ser una obra polivalente, es necesario un equilibrio entre el todo y las partes. Hay un límite en el número de hispanoamericanismos más allá del cual el Diccionario actual perdería su razón de ser. Y mantener el statu quo puede ser limitadamente útil para cierto público, pero no podrá dilatarse por mucho tiempo lo que está exigiendo el mundo hispánico del siglo XXI. Porque el problema real de los hispanoamericanismos académicos es que carecen de la información léxica habitual que está presente en otros diccionarios modernos. 


\section{EL DICCIONARIO HISTÓRICO}

Que en España una obra lexicográfica se proclame continuadora y descendiente de una tradición que arranca del siglo XVIII, merece, desde luego, todo el aplauso, pues no suele ser frecuente en este país que las obras de las instituciones fructifiquen tanto tiempo y con tanta vitalidad. Sin embargo, cómo se enfoque la resolución de las tensiones entre tradición y modernidad, pasado y futuro, es decisivo para que el resultado del trabajo tenga valor actualmente y no se convierta en un testimonio histórico, poco útil para las necesidades modernas. Cualquier lengua tiene la capacidad de adaptarse a los desafíos sociales, culturales, históricos y científicos que se le plantean. Si el Diccionario académico no es capaz de ajustarse al ritmo de adaptación de la lengua española, la fractura entre el Diccionario y la lengua culta habitual será cada vez más profunda. Ello acarreará dos graves consecuencias: a) la capacidad normativa del diccionario disminuirá notablemente; b) los usuarios limitarán su confianza en la Institución.

Según se expone en el prólogo, las dos ideas fundamentales que han presidido la elaboración de esta edición han sido mantener actualizado el cuerpo de la obra y acomodar el contenido tradicional a la estructura fijada en la Nueva planta. La obligación estatutaria de mantener actualizado el cuerpo de la obra en cuanto a los términos en ella registrados (p. XXVII) se despliega según un esquema lógico en adiciones, supresiones y adiciones-supresiones (enmiendas). Me parece que todos debemos preguntarnos si la función del Diccionario es conservar la tradición o servir de diccionario usual de la lengua de nuestros días. Y, si ésta debe ser la finalidad del Diccionario, la Academia debería serenamente sopesar las razones que aduce para conservar tantas voces arcaicas (anticuadas o desusadas en terminología académica). ¿Está convencido alguien seriamente de que con el Diccionario de la Academia pueden leerse los textos del Siglo de Oro? Los textos del Siglo de Oro deben leerse en ediciones bien anotadas y, a pesar de ello, en ocasiones son difíciles de leer. Desde luego no conozco a ningún filólogo que se atreva a editar un texto anotándolo con una edición moderna del Diccionario académico. En cambio, para esta labor resulta insustituible el Diccionario de Autoridades. A pesar de las cifras que confiesa el prólo- 
go académico, me parece exagerada la timidez de la Academia en la poda de lemas y acepciones. Parece, incluso, que la Academia no solo muestra una reverencia por la nomenclatura de las ediciones anteriores sino que acrecienta en algunos casos la tradicionalidad heredada. Todos conocemos el incierto futuro del Diccionario Histórico. Decida lo que decida la Academia sobre un instrumento como éste, imprescindible para cualquier trabajo filológico, me parece que la Academia no puede ligar el Diccionario usual al destino del Diccionario Histórico.

Probablemente se necesitaría en la Academia habilitar el empleo de "matapalabras" que ejercía un personaje de Perec:

Cinoc, que tenía a la sazón unos cincuenta años, ejercía una profesión curiosa: como decía él mismo, era "matapalabras": trabajaba en la actualización de los diccionarios Larousse. Pero, mientras otros redactores se dedicaban a la búsqueda de voces y significaciones nuevas, él, para dejarles sitio, debía eliminar todas las palabras y acepciones que habían caído en desuso (1988: 341).

El matapalabras académico debería suprimir de la manera más indolora posible los lemas y las acepciones anticuados y desusados, y bastantes definiciones que no corresponden a las realidades físicas o mentales actuales. Hace pocos años José Antonio Pascual, poco sospechoso de antiacademicismo, señalaba en una conferencia sobre "Los arcaísmos en un diccionario de uso" cómo ninguna razón justificaba que la nomenclatura de esta clase de diccionarios cargara con el peso de una información inútil para el usuario aunque, quizá, divertida.

Me parece que la Academia sigue contando excesivamente con los arcaísmos. No importa la cantidad de acepciones o lemas que se hayan suprimido. Por ejemplo, mantiene un verbo como apelar', "intr. Dicho de dos o más caballerías: ser del mismo pelo o color". Ya Cuervo, si no recuerdo mal, dudaba de este significado. Se documenta por primera vez con este sentido el participio apelado en el Diccionario de la Academia de 1770, sin ningún ejemplo. El verbo apelar $^{2}$ se incorpora en el Suplemento de la edición de 1803. La última edición tampoco incluye ejemplos. El Diccionario Histórico de 1933 no ejemplifica el verbo, pero en el lema apelado se lee: "dícese de dos o más caballerías del 
mismo pelo o color" y se incluye un ejemplo muy interesante: "Todos llevaban casacas encarnadas, galoneadas, los caballos apelados y los aderezos llenos de cascabeles (F. Azara, Descripción del Paraguay, ed. 1847 , p. 78)". No sé si el contexto permite señalar sin lugar a dudas que los caballos fueran del mismo color. En el CREA los ejemplos de apelado (82) se refieren mayoritariamente a apelar (alzarse judicialmente) o a apelar (llamar), igual que apelados (6) apeladas (1) y apelada (50). Sin embargo, el CORDE nos reserva una sorpresa valiosa. Un ejemplo de apeladas que no se relaciona con apelar (llamar o alzarse) sino con pelo, pero no con pelo de colores, sino con la "presencia de pelo":

También a veces hay quien vende por cabrito los abortos de vaca del tamaño del anterior; mas para conocer este abuso se advertirá lo siguiente: el feto de vaca es en el todo de sus formas de más anchura; su cabeza carece de largas orejas con pelo, y de dientes incisivos en la boca, cuando el cabrito tiene las orejas largas y algo apeladas, y los dientes son completos y colocados en su lugar.

Me imagino que la Academia dispone de más documentación para definir el adjetivo en la última edición como "Dicho de dos o más caballerías o toros: del mismo pelo o color". La tradición académica ha relacionado apelado con caballerías. Si mi información no es equivocada, que puede serlo, sin suficientes argumentos. Tampoco dispongo ahora de la información que se haya manejado sobre los toros. Desde luego, el CREA, como he comentado, no nos resuelve el problema. De todas maneras, sea apelar un fantasma o un simple arcaísmo, ¿qué finalidad tiene su inclusión sin ningún ejemplo ni marca en el Diccionario?

Otro caso curioso de acepción desusada, por inexistente, es la ${ }^{\circ} 9$ del verbo encarnar: "Dicho de una espada, de una saeta o de otra arma: introducirse por la carne". Como muy bien demostró Robert Jammes (1996), es un error que se documenta en Autoridades, nacido de la equivocada interpretación que hacen los autores del primer Diccionario académico del ejemplo gongorino de la Fábula de Píramo y Tisbe. He aquí los versos que provocaron el despiste: 


\begin{abstract}
Al fin en Píramo quiso
encarnar Cupido un chuzo,

el mejor de su armería,

con su herramienta al uso.
\end{abstract}

No deja de sorprenderme que en esta edición haya desaparecido la marca de ant. que ha venido acompañando a pesadura a lo largo de su historia. Cuando entra por primera vez en el Diccionario, en 1803, aparece marcado como ant. Con el sentido de 'gravedad' o 'peso' llega con la marca de ant. hasta 1956. En la edición de 1970 conserva la marca de ant. para la acepción de 'calidad de pesado' y se suprime para la de 'fuerza de gravedad', situación que permanece en el Diccionario actual. No dispongo de datos para saber el porqué de tal cambio. La tradición española para 'fuerza de gravedad', además de gravedad, contaba con pesadumbre, pesadez y, más tarde, probablemente por influjo del francés, con pesantez y gravitación. Graveza, que también se documentaba, se refería al peso o a las nociones de carácter, etc. de gravedad. En aquel momento, 1803, se admitía pesadura como arcaísmo, más en relación con 'cualidad de pesado' que con 'fuerza de gravedad'. No conozco textos de Física del siglo XIX que utilicen pesadura en vez de gravedad. En el CREA no se documenta y en el CORDE aparecen 28 casos, el más moderno, si no recuerdo mal, de 1509. Pesadura se documenta algunas veces en los buscadores de Internet (sobre todo en relación con México) en el sentido de 'peso'. En conclusión, hubiera sido una idea acertada suprimir pesadura o, al menos, marcarla como de México.

Recordemos, para acabar con el tema de los arcaísmos, la permanencia de formas medievales con poco interés en un Diccionario usual: homicillo (lo normal era homezillo/homecillo, parece una lectura equivocada); apostoligal, apostóligo (que remiten a apostólico, lema de uso limitado ya en el siglo XVI), clin (que remite a crin). No parece muy oportuno que aparezcan en el Diccionario. Como tampoco resulta muy plausible marcar actualmente garrotillo y secundinas como voces de medicina.

Mi intención era señalar que en el siglo XXI un Diccionario general de uso no puede ser a la vez un diccionario histórico resumido, un dic- 
cionario dialectal y un diccionario hispanoamericano. Para esta situación se han inventado las series de diccionarios. Sobre todo, porque creo que las informaciones anticuadas o desusadas y dialectales, llenas de inexactitudes a veces, ocupan el lugar de otras que podrían interesar a los lectores actuales. Si dejamos que los arcaísmos nos ocupen el tiempo, además del espacio físico, será difícil conseguir un diccionario que pueda responder a las preguntas que nos hace el siglo XXI. Es verdad que, a diferencia de otras ediciones, el Diccionario ha acrecentado considerablemente los neologismos recientes. Sin embargo, conviene recordar que la difusión del conocimiento, aunque sea superficial, se ha acelerado. Los campos técnicos y científicos han crecido vertiginosamente. Por ello, no se puede esperar medio siglo, como antaño, a ver si la renovación léxica se va a consolidar o no. Por ello, la aceptación razonada de los neologismos debe ser más rápida y, también, más fácil. Me fijo solo en un ejemplo, citado en el prólogo (p. XXVIII): mediterraneidad y mediterraneísmo. Se advierte que se documentan en el corpus académico pero no "para ser objeto de propuesta". Efectivamente, en el CREA aparece cinco veces mediterraneidad, y ninguna mediterraneísmo. Esta diferencia la muestra bien el Diccionario del español actual (en adelante DEA), donde se admite mediterraneidad, pero no mediterraneísmo. A la misma conclusión podemos llegar si se consulta algún buscador de Internet. Comprobaremos que mediterraneidad está bien instalado en el español, que se usa en España y mucho más en Hispanoamérica. También podremos comprobar que mediterraneísmo casi no está documentada y es una voz de 'búsqueda de estilo' en el contexto de un escrito. Por tanto, mediterraneidad hubiera resultado un neologismo muy aceptable en el Diccionario y mediterraneísmo hubiera resultado un neologismo relativamente forzado. ¿Por qué no se incluyó mediterraneidad? Pero la necesidad de aceptar y normalizar los neologismos, más o menos opinable, se hace absolutamente inaplazable con los neologismos científicos. La inclusión en todos los periódicos del mundo hispánico de páginas de divulgación científica y la extensión de nuevas técnicas y nuevos instrumentos entre capas relativamente amplias de la población obligan a un trabajo de organización, definición y coordinación del léxico contemporáneo, léxico absolutamente imprescindible en un diccionario de lengua actual, tal como 
puede comprobarse en los nuevos diccionarios de las principales lenguas europeas de cultura. Me parece más importante planear bien esta tarea que recoger algunos neologismos juveniles (aunque me parece acertado el haberlos recogido).

\section{DICCIONARIO DIALECTAL HISPÁNICO}

Las corrientes regionalistas a finales del siglo XIX, el desarrollo de los atlas lingüísticos y de la dialectología en el siglo XX propiciaron la entrada de dialectalismos en el Diccionario de la Academia. Es cierto que ya en Autoridades se atiende a las variedades diatópicas, pero en las ediciones del siglo XX se han incorporado excesivas voces y acepciones dialectales. Una representación dialectal muy nutrida no es censurable por sí misma, pero cuando se alía a un número de marcas dialectales o regionales, a veces superpuestas, y a una información de la distribución geográfica de las voces que no siempre inspira confianza, puede convertirse, como los arcaísmos, en un lastre. La información dialectal del Diccionario no inspira excesiva confianza. Las razones son las mismas que he expuesto ya más arriba. Probablemente las marcas que acompañan a algunas voces o acepciones no están equivocadas, pero tienen poca utilidad porque no expresan toda la verdad (ni la extensión geográfica actual, ni la consideración social, ni el uso, etc.). Por otro lado, la superposición de marcas (provincias, dialectos, regiones) no deja de resultar algo incoherente. Veamos un ejemplo:

Supongamos que todavía algún propietario guadaña un prado y después decide abarañar los baraños. El baraño es, según el Diccionario, voz salmantina, leonesa y zamorana, pero abarañar solo es salmantina. No tengo ninguna documentación que me permita afirmar otra cosa y me imagino que la Academia habrá consultado las encuestas o la documentación del atlas de la región. De hecho, tanto baraño como abarañar entran en la edición de 1925 y en esta última se han modificado las marcas: baraño hasta 1992 figuraba solo como salmantinismo. A pesar de todo, no deja de intrigarme que abarañar solo sea salmantinismo. ¿Hipercriticismo? Quizá, pero nacido de las numerosas inexactitudes que se notan en el ámbito dialectal. Como no hay que esforzarse espe- 
cialmente en demostrar las razones de esta actitud desconfiada, pongo otro ejemplo, absolutamente normal. En la actual edición se documenta Albericoque ("m. Ar. y N. Burg. y Méj. albaricoque"). Los duendes informáticos, tan socorridos en estas ocasiones, han borrado de la lista de abreviaturas oficiales $N$. Burg. No se incluyen ni $N$. ni $N$. Burg., ¿Norte de Burgos? A cualquiera le puede suceder, y no merece más comentarios. Ahora bien, se consulta Albérchigo y, dejando de lado la descripción del fruto, francamente divertida, en la tercera acepción se define como albaricoque en Cádiz, Huelva, Sevilla y Jaén. Mi sorpresa ha sido considerable, porque en mi Salamanca infantil nadie distinguía los albérchigos de los albaricoques. He pensado que podía deberse a un familectos, pero el DEA viene en nuestra ayuda: "Albérchigo m (reg.) Albaricoque (fruto y planta)". Es decir, el DEA marca albérchigo como regional (palabra general en un ámbito geográfico determinado de muy diversa extensión), porque los errores de este tipo [atribución geográfica] son innumerables en los diccionarios.

Aun admitiendo que en la presentación de la información dialectal no se hayan colado numerosas inexactitudes, creo sinceramente que sobran gran parte de los dialectalismos, tal como se presentan en la Academia. Todas las personas de mi generación que pasaron por la Facultad de Filología tuvieron que comentar un famoso texto asturiano en el que una cargadora del carro de hierba le exigía perentoriamente al cargador: "Apúrreme la soga, chachu". Otras veces se apurría la "borona seca" y la explicación podía adentrarse por senderos peligrosos, porque se debía explicar la diferencia entre "borona seca" y "borona seco", había que citar el neutro de materia, etc. Todo esto y muchas cosas más he recordado al encontrarme con el lema apurrir en la actual edición del Diccionario académico. ¿Es necesario apurrir en un diccionario del español actual, por más que se documente en Asturias y en Cantabria? $\mathrm{Y}$ ¿qué decir del Abinar, rural y vulgar ahora, y en la edición anterior propio de Burgos, León y Salamanca?

En esta edición del 2001 se documenta también adonecer "intr. Ál.

Neologismo poco recomendable. 
y Cantb. Aumentar; dar de sí" (se ha suprimido la referencia a Salamanca y la Rioja de 1992). Pero ¿qué o quién adonece? ¿Puedo escribir que el negocio adonece, puedo esperar oír que el niño adonece? ¿Adonece un jersey? ¿Es de uso general? ¿Se usa en serio?... En fin, parece que no es necesario insistir en lo evidente.

\section{RESUMEN FINAL}

El nuevo rumbo del Diccionario Académico me ha sugerido repasar algunas cuestiones que me han sorprendido. Hubiera podido detenerme en otras varias, pero las que me han ocupado me parecen fundamentales. No he recogido ni una lista de errores ni un conjunto de correcciones o adiciones. Al analizar algunos ejemplos concretos he intentado mostrar cómo es necesario concebir el Diccionario de otra manera. Para fundamentar la opinión que he expuesto he debido mostrar algunos errores, que son sólo ejemplos elegidos, en muchos casos, al azar. Como indicaba al principio, no faltan los errores en el Diccionario, exactamente igual que sucede en cualquier otro que se analice. Ahora bien, pudiera ser que el análisis de algún error fuera a su vez erróneo y el texto académico resultara perfecto en ese punto. En este caso, ruego que se olvide el ejemplo. A pesar de todo, creo que la argumentación general no perdería su valor porque -insisto- los errores señalados funcionan como ejemplos y, en la arquitectura general de la crítica, un ejemplo podría ser sustituido por otro parecido.

La cuestión fundamental que debe preocuparnos a todos, me parece, es que el Diccionario, que ha cambiado de rumbo, necesita, probablemente, otro rumbo distinto. En las advertencias para el uso de este Diccionario (pp. XXXIII y ss.) puede comprobarse cómo, por fin, el Diccionario académico se parece mucho a otros diccionarios en los procedimientos de presentación, remisión, entradas, participios, etc. Se puede estar de acuerdo o en desacuerdo con las soluciones elegidas, se puede pensar que se ha llegado a buen puerto o que se ha naufragado, pero el planteamiento es razonable y no merece la pena detenerse aquí en ello. Sin embargo, sí me preocupan otras cuestiones que considero importantes: a) La Academia tiene que incluir decididamente ejemplos. 
Si en todas las acepciones y lemas discutibles se dispusiera de ejemplos, la discutibilidad (que no figura en el Diccionario) sería muy escasa. b) El segundo problema, y el más importante, es que, en realidad, este Diccionario es un aperitivo del Diccionario que debemos esperar en este nuevo siglo, porque las definiciones no se han revisado en esta edición. Creo, sinceramente, que tienen razón los que consideran que la definición es la reina de la lexicografía. ¿Cómo vamos a juzgar un diccionario que ha dejado a la reina en tierra? c) El tercer problema, que ha quedado patente de pasada, es la dificultad de elaborar un buen diccionario contemporáneo sin un buen diccionario histórico. La Academia debe cambiar la dirección. No debe disimular el léxico contemporáneo entre términos anticuados y desusados porque no disponemos de diccionario histórico. Es mejor elaborar un diccionario histórico razonable para poder organizar convenientemente el léxico actual.

El Diccionario, en conjunto, conviene repetirlo, es una obra meritoria, lejos de la perfección, pero útil. Cuando se revisen sus definiciones podrá juzgarse con más acierto. Porque ahora, no creo que nadie se atreva a juzgar un Diccionario de la Lengua Española del año 2001 que define la fragata (clase de barco que se ha enviado al Golfo Pérsico) como "buque de tres palos con cofas y vergas en todos ellos". No se puede juzgar a un diccionario por una definición, es cierto, pero las definiciones del Diccionario de la Academia están pidiendo desde hace años una renovación total. Si alguien encuentra una oferta de un cupé, debe saber que se puede encontrar con una berlina (coche de caballos cerrado, de dos asientos comúnmente) o con un compartimento situado delante de la baca (en las antiguas diligencias). Y si ya tiene un cupé, aunque no sea de caballos, y un empleado de una gasolinera le ofrece gasoleno, debe entender gasolina. Según la entrada del Diccionario, sin ninguna marca, es preferible gasolina, pero gasoleno no es voz extraña (se documentó en el siglo XIX, pero se impuso el galicismo gasolina). Pero analizar las definiciones nos puede llevar a otras historias...

En resumen, me parece importante el preámbulo y el prólogo, y las páginas referidas a la organización del diccionario resultan satisfactorias. Confieso sinceramente que han entrado bastantes neologismos, a 
pesar de que falten muchos. El listado de hispanoamericanismos ha sido cuidado mucho más que antes; se nota que hay algún ejemplo más... Pero, en esta dirección queda todavía mucho camino que andar. Es relativamente secundario que se redacten las definiciones de acuerdo con el contorno; mejor es que se planteen seriamente los problemas desde la perspectiva de la gramática léxica, y que se estudien los argumentos de las palabras. También es fundamental preocuparse por la estructura profunda de las definiciones y no por las fórmulas superficiales; que se cuente con la organización meronímica cuando sea necesario, etc. Me parece, por último, que deberían corregirse las etimologías erróneas. Por ejemplo, tontillo ('faldellín'...) es un italianismo y no creo que tenga nada que ver con tonelete. Sería bueno, también, que el Diccionario fijara el origen inmediato y no la etimología lejana. Metro 'medida de longitud' es un galicismo, aunque su etimología sea el griego, etc.

Si me he detenido tanto en el Diccionario es, quizá, porque siempre me ha halagado la opinión de T. de Mauro, autor que envidiaba que la lengua española dispusiera de una Academia y de un Diccionario oficial. Con la nueva edición el Diccionario ha emprendido un cambio de rumbo importante, pero insuficiente. Para servir en las travesías que se avecinan necesitará una remodelación esencial y una velocidad de maniobra muy superior a la que muestra en la actualidad. Se trata, en definitiva, de pasar de la fragata de vela a los modernos barcos con todos los últimos instrumentos para navegar. 


\section{BIBLIOGRAFÍA}

DEA (1999): Manuel SeCo, Olimpia de ANDRÉs y Gabino RAMos, Diccionario del español actual, Madrid, Aguilar.

GaRrigA, Cecilio (2001): "Sobre el Diccionario Académico: la 12a edición (1884)", en A. Ma Medina Guerra, coord., Lexicografia Diacrónica, Málaga, Universidad de Málaga, 2001, pp. 263-315.

JAMMES, Robert (1996): “Góngora en el Diccionario de Autoridades", en Philologica (Homenaje al profesor Ricardo Senabre), Cáceres, Universidad de Extremadura, pp. 247-272.

LANE, Philippe (1992): La périphérie du texte, Paris, Nathan Université. PEREC, George (1988): La vida instrucciones de uso, trad. de Josep Escué, Barcelona, Anagrama.

REY, A. (1983) : "Norme et dictionnaires (domaine du français)", en É. Bédard y J. Maurais, La norme linguistique, Québec, Conseil de la Langue Française, 1983, pp. 541-569.

SCHWEMMER, O. (1978): “Apelación y argumentación. Tareas y límites de una filosofía práctica", en Friedrich Kambartel, comp., Filosofía práctica y teoría constructiva de la ciencia, trad. de Ernesto Garzón Valdés, Buenos Aires, Alfa, pp. 157-221 (original Shurkamp Verlag, 1974).

Valbuena, Antonio de [Miguel de la Escalada] (1896): Fe de erratas del Diccionario de la Academia, IV, Madrid, Victoriano Suárez. 